\title{
A Cortesia em Pedidos em Italiano: Um Estudo Comparativo da Percepção de Brasileiros e ITALIANOS
}

\author{
Mayara Da Silva Neto* \\ ElisabetTa Santoro**
}

\begin{abstract}
RESUMO: Partindo de enunciados que contêm pedidos de falantes nativos de italiano, a pesquisa que apresentamos neste artigo buscou identificar e analisar as percepções da cortesia por parte de brasileiros e italianos e suas possíveis justificativas. Foi utilizado um corpus (obtido por meio de role plays semiabertos) composto de vídeos nos quais interagem duplas de falantes nativos de italiano que realizam pedidos com baixo e alto grau de imposição. Por meio de um formulário on-line, oito vídeos, selecionados a partir do referido corpus, foram submetidos a dois grupos de informantes brasileiros (estudantes de italiano no início e em uma fase avançada do estudo da língua) e dois grupos de informantes italianos (residentes no Brasil e na Itália). Com base na avaliação dos vídeos, procurou-se verificar se há, nos dados fornecidos por italianos e brasileiros, disparidades ou semelhanças nos níveis de cortesia atribuídos aos pedidos mostrados; quais elementos são indicados para justificar a escolha desses níveis; se existe alguma correlação entre estes e as justificativas apresentadas; e, por fim, na comparação entre os grupos, se e em que medida o contato prolongado com a outra língua e cultura pode alterar a percepção de brasileiros e italianos. Identificamos que há mais similaridades que divergências nas percepções da cortesia entre os grupos. PALAVRAS-CHAVE: cortesia; língua italiana; pedidos; percepção; pragmática linguística.
\end{abstract}

*Bacharel em Letras com habilitação em Português e Italiano/Mestranda do Programa de PósGraduação em Língua, Literatura e Cultura Italianas, FFLCH/USP.

** Docente da Area de Língua e Literatura Italiana e do Programa de Pós-Graduação em Língua,

Literatura e Cultura Italianas, FFLCH/USP.

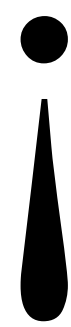


ABSTRACT: Partendo da dialoghi che contengono richieste di parlanti nativi di italiano, la ricerca che presentiamo in questo articolo si è proposta di identificare e analizzare le percezioni della cortesia da parte di brasiliani e italiani e le loro possibili motivazioni. È stato utilizzato un corpus (registrato a partire da role plays semiaperti), composto da video nei quali interagiscono coppie di parlanti nativi di italiano che realizzano richieste con basso e alto grado di imposizione. Servendoci di un questionario on-line, abbiamo sottoposto otto video, selezionati a partire dal corpus citato, a due gruppi di informanti brasiliani (studenti di italiano all'inizio e in una fase avanzata dello studio della lingua) e due gruppi di italiani (residenti in Brasile e in Italia). Sulla base della classificazione dei video, si è cercato di osservare disparità e analogie nei livelli di cortesia attribuiti da brasiliani e italiani alle richieste selezionate; quali elementi vengono indicati per giustificare la scelta realizzata; se esiste una correlazione tra i livelli di cortesia e le motivazioni presentate; e, per finire, nel confronto tra i gruppi, se e in che misura il contatto prolungato con l'altra lingua e cultura può modificare la percezione di brasiliani e italiani. Abbiamo identificato la presenza di più similarità che divergenze nella percezione della cortesia dei gruppi di informanti.

PAROLE CHIAVE: cortesia; lingua italiana; richieste; percezione; pragmatica.

ABSTRACT: Using dialogues with requests made by native speakers of Italian, the research we present in this paper tried to identify and analyze the perceptions of politeness of Brazilians and Italians and their possible motivations. We used a corpus composed by video and audio recordings in which pairs of native speakers of Italian perform role-play requests with low and high degree of imposition. We submitted an online questionnaire with eight videos selected from the above mentioned corpus to two groups of Brazilian (students of Italian at the beginning and at an advanced stage of their studies on the language) and two groups of Italian (living in Brazil and in Italy) informants. Based on their judgment about the videos, we tried to 
identify: if there were similarities or differences in the level of politeness attributed by Brazilians and Italians to the selected requests; which reasons informants gave to justify their choices; if there is a correlation between those choices and the reasons given to justify them; and, finally, comparing all these information, whether and to what extent prolonged contact with the other language and culture may change the perception of politeness of Brazilians and Italians. Our results revealed that there are more similarities than differences in the informants' perception of politeness. KEYWORDS: politeness; Italian language; requests; perception; pragmatics. 


\section{Introdução}

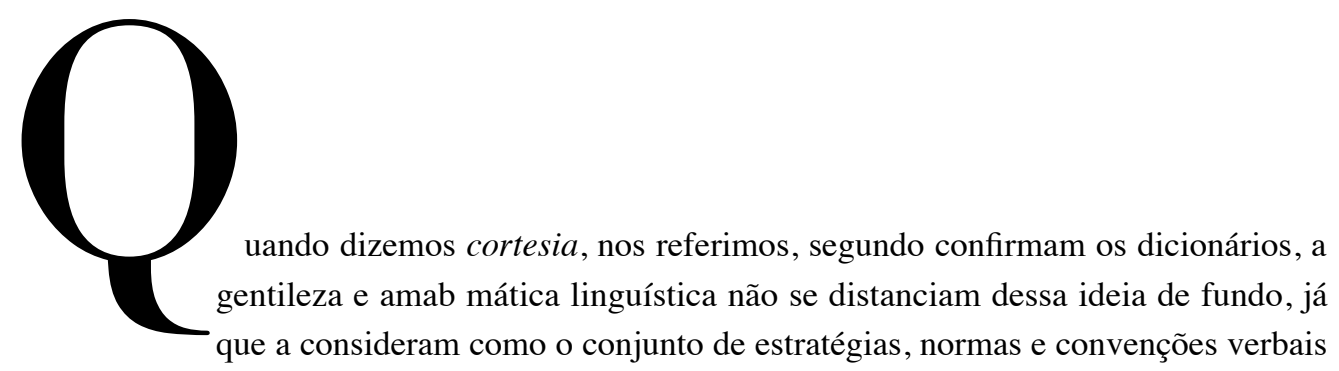

adotadas por uma comunidade de fala para conter a conflitualidade e favorecer a harmonia na interação verbal. É essencial, no entanto, considerar que a cortesia não é um valor absoluto, mas envolve um grande número de nuances que podem, em parte, depender de avaliações subjetivas, mas estão fortemente relacionadas com as normas socialmente compartilhadas em uma determinada cultura ${ }^{1}$.

1 Nasce disso o interesse da Pragmática Cross-Cultural, que busca comparar normas pragmáticas em duas ou mais línguas e culturas (ver, entre outros, BLUM-KULKA, HOUSE e KASPER, 1989). 
Voltaremos mais adiante, com mais detalhes, aos estudos sobre cortesia linguística, mas nos interessa evidenciar, desde o início deste texto, que o fato de as diferenças culturais serem tão determinantes na definição da cortesia explica a importância de se debruçar sobre esses fenômenos quando o nosso interesse diz respeito à relação entre duas ou mais línguas e culturas: as normas diferentes podem causar atritos, gerar dificuldades na compreensão mútua e, em última análise, impedir uma relação harmoniosa entre os indivíduos.

A situação em que se aprende ou se ensina uma língua estrangeira é uma das que fazem entrar em contato duas línguas e duas culturas, e podem criar conflitos se os atores envolvidos não tiverem consciência das diferenças e não entenderem o ensino e a aprendizagem de uma língua como algo que vai muito além de gramática e listas de palavras. Saber que o outro pode perceber de forma diferente o que falamos e observar de que maneira são realizados na outra língua determinados atos de fala pode contribuir para que se busque uma compreensão mais profunda, evitando avaliações que podem muitas vezes atribuir ao "caráter" algo que, na verdade, é determinado pelas diferenças de cada língua e cultura (THOMAS, 1983).

Preocupadas com essas questões, procuramos investigar as percepções da cortesia de brasileiros e italianos a partir de um ato de fala específico - o pedido - realizado por falantes nativos de italiano, para, em seguida, analisar e tentar entender o que motivou similaridades ou diferenças nas percepções relatadas pelos informantes.

Dado que são poucos ou inexistentes os estudos que comparam a percepção da cortesia de falantes de italiano e de português brasileiro, uma pesquisa dessa natureza pode ampliar os conhecimentos nesse sentido, sistematizando e explicando aspectos que são muitas vezes discutidos sem embasamento teórico e sem dados empíricos. Pensando no ensino e na aprendizagem do italiano no Brasil, os resultados dessa pesquisa podem ajudar brasileiros a evitar interpretações negativas infundadas e outros problemas de comunicação. Para os italianos, participar de uma pesquisa desse tipo e conhecer seus resultados é um modo de refletir sobre seu próprio comportamento linguístico e de desenvolver uma maior consciência de suas peculiaridades.

\section{Sobre a cortesia e o pedido}

Antes de descrever os objetivos, a metodologia e os resultados da pesquisa que apresentaremos neste artigo, explicitaremos a seguir alguns dos pressupostos teóricos que a nortearam.

O primeiro passo é definir melhor a cortesia linguística, tentando resumir o que vem sendo 
dito sobre ela desde meados do século XX. Segundo Mariottini, “com 'cortesia' se indicam todas aquelas estruturas recorrentes na língua escrita e falada que manifestam um comportamento comunicativo cooperativo e respeitoso" (2007, p. 9)2 . Para manifestar cooperação e respeito, os falantes utilizam um conjunto de estratégias que determinam a escolha de certas formas linguísticas e buscam, assim, compensar a potencial agressividade ou mitigar ações que podem se constituir como uma ofensa para o destinatário. O foco está, portanto, no comportamento verbal e na ideia de a cortesia ser parte da função interpessoal da linguagem. $\mathrm{Na}$ análise da cortesia, é determinante refletir sobre as relações sociais e considerar o papel do afeto e do mútuo reconhecimento, além das diferentes relações que se criam entre indivíduos a partir dos pares poder/solidariedade e distância/proximidade (cf. MARIOTTINI, 2007, p. 10).

Essas ideias já estavam em Grice (1975 [1967]), no seu Princípio de Cooperação e nas Máximas Conversacionais, sendo a máxima do Modo a mais ligada à ideia de cortesia, uma vez que, segundo Grice, ela não considera o que ("what") é dito, mas a maneira (“how") com a qual algo deve ser dito. Em 1973, Robin Lakoff, no artigo The logic of politeness; or, minding your P's and $Q$ 's, considera ser cortês uma das duas grandes regras da competência pragmática, sendo a outra regra ser claro. Sobre isso, Bazzanella (2008, p. 181) lembra que, caso essas duas regras entrem em conflito, a que diz respeito à cortesia tende a ser priorizada pelos falantes: se um enunciado não for claro, é comprometida a compreensão, mas se for descortês, é a relação entre os interlocutores a sofrer as consequências. Brown e Levinson (1987), em Politeness: some universals in language usage, ligam a ideia de cortesia à de preservação das faces - isto é, a imagem pública que cada indivíduo possui. A face negativa representa o desejo do indivíduo de ter sua liberdade de ação respeitada; e a positiva, a imagem que cada indivíduo expõe à sociedade, esperando que seja aceita e respeitada. Esse desejo de preservação recíproca das faces $e ́$ o que motiva, segundo Brown e Levinson, a utilização de estratégias de cortesia e, segundo os autores, ainda que varie de acordo com as regras das diferentes comunidades/culturas, o conceito de face $e ́$ universal ${ }^{3}$.

Vejamos agora como entenderemos o ato de fala "pedido", que pode ser visto como "uma tentativa de fazer alguma coisa simplesmente falando" (TRASK, 2004, p. 42). A referência à ideia de que "falar é agir" e, portanto, à Teoria dos Atos de Fala remete a Austinn, que divide os atos de fala em locucionários (ato de dizer), ilocucionários (ação realizada por meio do dizer) e perlocucionários (efeitos causados no interlocutor por meio do dizer). O pedido pertence à categoria dos ditos atos ilocucionários e é realizado com verbos de tipo exercitivo, ligados ao

2 “Con 'cortesia'si indicano tutte quelle strutture ricorrenti nella lingua scritta e parlata che manifestano un comportamento comunicativo cooperativo e rispettoso." Exceto onde indicado, as traduções deste texto são de nossa autoria. 3 Afirmam Brown e Levinson: "Central to our model is a highly abstract notion of 'face' [...], which (we argue) is universal, but which in any particular society we would expect to be subject of much cultural elaboration." (1987, $\mathrm{p}$. 13). A ideia de universalidade defendida por Brown e Levinson foi duramente criticada por muitos dos estudiosos que, depois deles, se dedicaram a essas reflexões (ver, entre outros, PIZZICONI, 2003).

4 A referência é à renomada obra de J. Austin, How to do things with words, publicada postumamente em 1962. 
exercício de poder, direito ou influência. Mais tarde, Searle ${ }^{5}$ propõe uma nova classificação das forças ilocucionárias envolvidas nos atos de fala e insere o pedido entre os atos ditos diretivos: um falante, por meio de um pedido, tem o intuito de direcionar as atitudes de seu interlocutor para chegar a um determinado resultado.

Concluindo esse rápido panorama do que foi escrito sobre os pedidos, citaremos Brown e Levinson (1987), para os quais o pedido é um Face Threatening Act (FTA), isto é, um ato de fala que ameaça a face positiva do falante (comprometendo sua imagem) e a face negativa do interlocutor (colocando em questão sua liberdade de escolha). O pedido, como qualquer FTA, nem sempre interfere com a mesma força, variando com base em três fatores: o grau de imposição, isto é, a relação custo-benefício que o ato traz consigo, a distância social e o poder relativo entre os interlocutores.

\section{Objetivos}

Podemos agora falar da pesquisa aqui apresentada, cujo objetivo principal era identificar de que modo a cortesia linguística em pedidos realizados por falantes nativos de italiano é percebida por brasileiros (divididos em dois grupos: um que estudava italiano há menos de dois anos e outro que se encontrava numa fase avançada de contato com a língua) e italianos (analisando separadamente os residentes na Itália e os residentes no Brasil). Além disso, o estudo buscou eliciar e analisar as possíveis motivações para as disparidades ou semelhanças encontradas nas percepções relatadas por brasileiros e italianos.

Com o intuito de aprofundar os objetivos iniciais do estudo, foram definidas as seguintes perguntas de pesquisa:

- Quais analogias e diferenças entre os grupos de informantes podem ser identificadas quanto ao nível de cortesia atribuído aos pedidos?

- Quais categorias podem ser reconhecidas nas justificativas fornecidas pelos informantes após a atribuição do nível de cortesia?

- É possível reconhecer uma correlação entre as diferentes categorias e o nível de cortesia? De que maneira?

5 A obra de J. R. SEARLE, intitulada Speech Acts. An Essay in the Philosophy of Language é de 1969. 
- O contato prolongado com a outra língua e cultura modifica a percepção da cortesia? Em que medida?

\section{Metodologia}

O corpus do qual foram extraídos os pedidos apresentados aos informantes ${ }^{6} e ́$ composto por 360 vídeos, 180 pedidos e 180 pedidos de desculpas, sempre realizados por falantes nativos de italiano. Esses falantes, em duplas, realizaram role plays que chamaremos semiabertos, nos quais um deles iniciava a interação a partir de um breve roteiro entregue por escrito, enquanto o outro respondia a partir da primeira fala do interlocutor. As interações se estendiam, sem restrição de tempo ou de turnos, até o momento em que os interlocutores considerassem realizado o ato de fala e concluída a interação. Vale esclarecer que o role play semiaberto é um método de coleta de dados que pode ser considerado de controle intermediário (levando em conta, em especial, a relação entre a variável dependente e a variável independente) (cf. SANTORO, 2012), em que o pesquisador informa ao falante, oralmente ou por escrito, a situação do ato de fala a ser realizado. Os roteiros (prompts) entregues a um dos integrantes de cada dupla para que realizasse os pedidos eram os seguintes:

60 corpus utilizado foi elaborado e gravado em áudio e vídeo por Santoro em 2011. A seleção da metodologia com a qual seriam coletados os dados e a própria gravação foram parte do estágio pós-doutoral realizado junto à Università di Modena e Reggio Emilia, com a supervisão de Gabriele Pallotti. 
1. Prompts entregues aos participantes dos role-plays

\begin{tabular}{|c|c|c|c|}
\hline Situazione & Prompt & Situação & Prompt \\
\hline Penna & $\begin{array}{l}\text { Sei per strada con un amico/un'amica } \\
\text { e vuoi scrivere il numero di telefono } \\
\text { di un annuncio che vedi passando. Ti } \\
\text { accorgi però di non avere una penna } \\
\text { con te... Che cosa dici? }\end{array}$ & Caneta & $\begin{array}{l}\text { Você está na rua com um amigo/uma } \\
\text { amiga e quer escrever o número de } \\
\text { telefone de um anúncio que você vê } \\
\text { passando. Percebe, porém, que está } \\
\text { sem caneta... O que você diz? }\end{array}$ \\
\hline Cellulare & $\begin{array}{l}\text { Sei per strada con un amico/un'amica } \\
\text { e sei in ritardo. Devi urgentemente } \\
\text { telefonare a un tuo amico che ha } \\
\text { fatto un lungo viaggio per venire a } \\
\text { trovarti. Il tuo cellulare per qualche } \\
\text { inspiegabile motivo non funziona } \\
\text { e non ci sono pubblici in giro. Non } \\
\text { resta che cercare un cellulare in } \\
\text { prestito per una telefonata... Che } \\
\text { cosa dici? }\end{array}$ & Celular & $\begin{array}{l}\text { Você está na rua com um amigo/uma } \\
\text { amiga e está atrasado. Você tem que } \\
\text { ligar com urgência a um amigo que } \\
\text { fez uma longa viagem para te visitar. } \\
\text { Seu celular por algum motivo não } \\
\text { funciona e não há telefones públicos } \\
\text { nas redondezas. Não resta opção além } \\
\text { de tentar emprestar um celular para um } \\
\text { telefonema... O que você diz? }\end{array}$ \\
\hline Bere & $\begin{array}{l}\text { Sei appena entrato a casa di un tuo } \\
\text { amico/una tua amica e hai sete. Che } \\
\text { cosa dici? }\end{array}$ & Beber & $\begin{array}{l}\text { Você acaba de entrar na casa de um } \\
\text { amigo/uma amiga e está com sede. O } \\
\text { que você diz? }\end{array}$ \\
\hline Temporale & $\begin{array}{l}\text { Sei appena entrato a casa di un tuo } \\
\text { amico/una tua amica bagnato fradicio } \\
\text { perché fuori sta piovendo a dirotto. } \\
\text { Hai bisogno di farti una doccia o } \\
\text { almeno di toglierti i vestiti bagnati. } \\
\text { Che cosa dici? }\end{array}$ & Temporal & $\begin{array}{l}\text { Você acaba de entrar na casa } \\
\text { de um amigo/uma amiga e está } \\
\text { completamente encharcado porque } \\
\text { está caindo um dilúvio. Você precisa } \\
\text { tomar um banho ou ao menos tirar a } \\
\text { roupa molhada. O que você diz? }\end{array}$ \\
\hline
\end{tabular}

Note-se que os prompts acima começam sempre com uma indicação espacial ("você está na rua" ou "você acaba de entrar na casa de um amigo"). Todos os role-plays foram realizados na rua ou, então, na casa de um dos interlocutores, pois foi aplicado o conceito de setting (SANTORO, 2012), que consiste em recriar, em situações como a de um role-play, o contexto e o ambiente em que os atos de fala em questão são realizados na vida real, com vistas a oferecer ao participante as melhores condições para que formule um ato de fala verossímil, pressupondo que um ambiente propício pode facilitar a recuperação de certas rotinas linguísticas dos informantes. 
Outro aspecto importante do corpus em questão é que as duplas de falantes tinham diversos tipos de relação pessoal e profissional, e na pesquisa procurou-se sempre respeitar a real relação dos informantes gravados. Para facilitar a análise, os graus de familiaridade foram separados em dois grandes grupos, conforme se vê no quadro abaixo:

Quadro 2. Grau de familiaridade entre os participantes dos role plays

\begin{tabular}{l|l}
\hline Grau de familiaridade & Condição \\
\hline $\begin{array}{l}\text { Médio-baixo } \\
\text { Indice de 0-5 }\end{array}$ & $\begin{array}{l}\text { Desconhecidos ou pessoas que se conheciam há pouco; pessoas cuja } \\
\text { relação era marcada por diferenças sociais. }\end{array}$ \\
\hline $\begin{array}{l}\text { Médio-alto } \\
\text { Ídice de 6-10 }\end{array}$ & Amigos e membros da família. \\
\hline
\end{tabular}

Como foi possível notar, os três fatores estabelecidos por Brown e Levinson (1987) para determinar o grau de ameaça à face negativa do interlocutor são contemplados e passíveis de observação nesse corpus: a distância social e a relação de poder, se pensarmos nos diversos graus de familiaridade entre os falantes e na eventual relação hierárquica entre eles, e o grau de imposição, se pensarmos no tipo de pedido e em sua relação custo/benefício, já que havia para cada pedido com alto grau de imposição também um cujo grau de imposição era baixo (pense-se na diferença entre pedir um celular para fazer uma chamada interurbana e uma caneta para anotar um telefone).

O caráter homogêneo do corpus fez com que fosse necessário estabelecer um critério que permitisse uma diferenciação e uma consequente viabilização da escolha de uma pequena quantidade de vídeos a ser apresentada aos informantes. Uma vez que em muitas pesquisas que realizam análises semelhantes àquela aqui relatada um aspecto crucial é a quantidade de modificadores utilizados no pedido (CARREL e KONNEKER, 1981; FAERCH e KASPER, 1989; NUZZO e GAUCI, 2012), decidiu-se que a quantidade de modificadores presente no ato de fala principal (head act) dos vídeos seria, além do tipo do pedido, dos graus de imposição e de familiaridade e do setting, o critério que determinaria a sua escolha. Nos quadros abaixo podem ser observados os pedidos e as características daqueles escolhidos para a pesquisa: 
Quadro 3. Características dos 4 tipos de pedidos

\begin{tabular}{l|l|l}
\hline Tipo de pedido & Grau de imposição & Setting \\
\hline Uma caneta para anotar uma informação (penna) & Baixo & Rua \\
\hline Um celular para fazer uma chamada (cellulare) & Alto & Rua \\
\hline Um copo d'água (acqua) & Baixo & Casa \\
\hline $\begin{array}{l}\text { Trocar as roupas ou tomar um banho após um } \\
\text { temporal (doccia / vestiti) }\end{array}$ & Alto & Casa \\
\hline
\end{tabular}

Quadro 4. Características dos vídeos escolhidos

\begin{tabular}{l|l|l|l|l|l}
\hline Número & $\begin{array}{l}\text { Tipo de } \\
\text { pedido }\end{array}$ & $\begin{array}{l}\text { Grau de } \\
\text { imposição }\end{array}$ & $\begin{array}{l}\text { Grau de } \\
\text { familiaridade }\end{array}$ & Contexto & Modificadores \\
\hline 1 & penna & baixo & $6-10$ & rua & per caso e per piacere \\
\hline 2 & penna & baixo & $0-5$ & rua & 0 \\
\hline 3 & cellulare & alto & $6-10$ & rua & un attimo \\
\hline 5 & cellulare & alto & $0-5$ & rua & [non è] che, per caso e avrebbe \\
\hline 6 & acqua & baixo & $6-10$ & casa & Subito \\
\hline 7 & acqua & baixo & $0-5$ & casa & devo e può \\
\hline 8 & doccia / vestiti & alto & $6-10$ & casa & 0 \\
\hline
\end{tabular}

Quanto à classificação dos modificadores encontrados em cada pedido, partiu-se daquela proposta por Nuzzo e Gauci (2012, p. 51), adicionando, contudo, ao grupo dos modificadores lexicais, uma categoria para as fórmulas ou marcas de cortesia e uma para os que chamamos "reforçadores". Ao grupo dos modificadores morfossintáticos, foi adicionada a categoria dos verbos modais. 
Quadro 5. Classificação dos modificadores presentes nos pedidos

\begin{tabular}{|c|c|c|c|}
\hline Tipo & Subtipo & Função & Exemplo \\
\hline \multirow{5}{*}{$\begin{array}{l}\text { Modificadores } \\
\text { morfossintáticos }\end{array}$} & Imperfeito & $\begin{array}{l}\text { Faz parecerem distantes da realidade o desejo ou } \\
\text { a necessidade daquele que faz um pedido. }\end{array}$ & $\begin{array}{l}\text { volevo sapere se mi potevi:.: \# } \\
\text { aiutare }\end{array}$ \\
\hline & Condicional & $\begin{array}{l}\text { Faz parecerem distantes da realidade o desejo ou } \\
\text { a necessidade daquele que faz um pedido. }\end{array}$ & avrei bisogno di un consiglio \\
\hline & Verbos modais & $\begin{array}{l}\text { Verbos que, ao acompanharem outros, } \\
\text { expressam o sentido de obrigação, proibição, } \\
\text { necessidade, possibilidade etc. }\end{array}$ & $\begin{array}{l}\text { [mi posso] fare una } . \text { piccola } \\
\text { doccia non so qualcosa }\end{array}$ \\
\hline & $\begin{array}{l}\text { Fórmulas } \\
\text { dubitativas }\end{array}$ & $\begin{array}{l}\text { Faz com que aquele que pede pareça em dúvida } \\
\text { sobre a possibilidade de que o pedido seja } \\
\text { atendido. }\end{array}$ & $\begin{array}{l}\text { non so se mi puoi aiutare per } \\
\text { decidere }\end{array}$ \\
\hline & $\begin{array}{l}\text { Interrogativa } \\
\text { negativa }\end{array}$ & $\begin{array}{l}\text { Faz com que aquele que pede pareça em dúvida } \\
\text { sobre a possibilidade de que o pedido seja } \\
\text { atendido. }\end{array}$ & $\begin{array}{l}\text { non è che tu hai magari il nome } \\
\text { di un loro album? }\end{array}$ \\
\hline \multirow{6}{*}{$\begin{array}{l}\text { Modificadores } \\
\text { lexicais }\end{array}$} & Duvidador & $\begin{array}{l}\text { Faz com que aquele que pede pareça em dúvida } \\
\text { sobre a possibilidade de que o pedido seja } \\
\text { atendido. }\end{array}$ & $\begin{array}{l}\text { lei non è che avrebbe per caso dei } \\
\text { cidì in offerta? }\end{array}$ \\
\hline & Atenuador & $\begin{array}{l}\text { Faz com que o pedido pareça custar menos ao } \\
\text { destinatário. }\end{array}$ & Non so \# un po’ $i$ cost $i$ \\
\hline & Reforçador & $\begin{array}{l}\text { Aumentam/reforçam a força ilocucionária do } \\
\text { elemento que acompanham. }\end{array}$ & $\begin{array}{l}\text { mi dai un bicchiere d'acqua } \\
\text { subito subito }\end{array}$ \\
\hline & Preenchimentos & Faz com que aquele que pede pareça hesitante. & $\begin{array}{l}\text { volevo che::: ehm cioè che mi } \\
\text { consigliassi un cidì }\end{array}$ \\
\hline & $\begin{array}{l}\text { Fórmulas de } \\
\text { cortesia }\end{array}$ & $\begin{array}{l}\text { Com os quais se pede explicitamente a } \\
\text { colaboração do interlocutor. }\end{array}$ & $\begin{array}{l}\text { \#\# hai per caso una penna per } \\
\text { piacere }\end{array}$ \\
\hline & Apelo & Busca chamar a atenção do destinatário. & $\begin{array}{l}\text { ascolti io l'ho chiamata:: perché } \\
\# 0 \_5 \text { dovrei fare un regalo }\end{array}$ \\
\hline
\end{tabular}


Para coletar os dados utilizou-se um questionário on-line (Google Docs) com a seguinte estrutura: i) saudação inicial e breve apresentação da pesquisa; ii) perguntas para traçar um perfil sociolinguístico dos informantes; iii) os oito vídeos, com legendas em italiano e os rostos dos participantes desfocados (para tutelar sua privacidade), seguidos de uma escala de cortesia de 1 a 5 e um espaço para que os informantes justificassem a escolha do nível de cortesia, explicitando os elementos que os haviam levado a atribuir aquele nível. O nível 1 era o mais baixo, o 2 médio-baixo, o 3 médio, o 4 médio-alto e o 5 alto.

Como dissemos, os informantes, contatados sempre por e-mail ou redes sociais, foram divididos em quatro grupos: Brasileiros 1 (BR1), estudantes brasileiros de língua italiana no início de seu percurso de aprendizagem; Brasileiros 2 (BR2), estudantes brasileiros de língua italiana em nível avançado; Italianos na Itália (IT) e Italianos no Brasil (ITB).

\section{Resultados}

Ao todo, foram consultados 82 informantes. O grupo BR1 contou com 19 informantes, predominantemente do sexo feminino e com média etária de 24,8 anos. No momento da pesquisa, eles haviam estudado a língua italiana por aproximadamente 14 meses, e 14 dos 19 participantes haviam frequentado cursos ministrados por docentes falantes nativos de italiano. Cabe dizer que essa pergunta foi inserida no questionário por considerarmos que poderia ser levado em consideração o contato de um aluno brasileiro com um falante nativo de italiano.

O BR2 foi composto de 22 informantes, em sua maioria mulheres, com uma idade, em média, mais elevada: 29,9 anos. O tempo de estudo de língua italiana era de, em média, 52 meses e 20 dos 22 informantes declararam já ter tido aulas com um professor falante nativo de italiano.

Os italianos na Itália (IT) eram 21, o gênero era predominantemente o feminino e a idade, em média, de 28,7 anos.

No grupo ITB havia 20 informantes com média etária em 48 anos. Quanto ao gênero, este foi o grupo mais equilibrado.

No questionário submetido aos informantes não havia categorias preestabelecidas que pudessem ser assinaladas para justificar as escolhas. Como o estudo tem caráter exploratório, nosso objetivo era que os próprios informantes trouxessem informações e pudessem indicar os elementos com base nos quais definiram para cada pedido avaliado uma determinada pontuação. Por conta disso, surgiram justificativas das mais variadas e, para sua avaliação, foi necessário 
criar categorias que permitissem agrupar as respostas e viabilizar uma melhor visualização e uma análise mais organizada, que nos desse a possibilidade de compará-las aos níveis de cortesia indicados. As categorias determinadas a partir das respostas dos informantes foram as seguintes:

1. Modificadores lexicais: além dos elementos citados na classificação de Faerch e Kasper (1989) e Nuzzo e Gauci (2012), os reforçadores e respostas do tipo "saudação" também estão incluídas nessa categoria (como fórmulas de cortesia);

2. Modificadores morfossintáticos: elementos indicados na classificação de Nuzzo e Gauci (2012) e verbos modais;

3 SUPPORTIVE MOVES OU MODIFICADORES EXTERNOS: justificativas (frequentemente denominadas "explicações" pelos informantes) que preparam ou acompanham os pedidos;

\section{Grau de imposição;}

\section{Grau de familiaridade;}

6. Entonação: casos em que os informantes forneciam justificativas como "tom de voz" ou simplesmente "tom";

7. Formas de tratamento: quando os informantes citavam o uso dos pronomes italianos $t u$ e $l e i$, que são traços típicos de tratamento informal e formal, respectivamente. Também aqui estão classificadas as respostas de tipo "tratamento formal" ou "informal";

8. Contexto: justificativas que evidenciavam a importância da motivação do pedido ou a urgência com que o falante precisava de ajuda;

9. Atitude do interlocutor: predisposição do interlocutor em realizar o pedido; 
10. Pedido (IN)Direto: menções sobre o caráter direto ou indireto do pedido;

\section{Pedido Percebido Como ordem;}

12. Aspectos diversos: a ordem das ações dos falantes (se primeiro cumprimentou e depois fez o pedido ou vice-versa), as impressões que a interação causava, a intenção que deixavam transparecer, características abstratas como "amabilidade" ou aspectos ligados ao respeito dos turnos de fala;

13. AusênCia de JuStificativa: casos em que houve respostas ambíguas ou de impossível interpretação.

Os resultados serão apresentados a seguir, organizados de modo a responder às questões colocadas para a pesquisa.

Em primeiro lugar, nos perguntamos quais analogias e diferenças poderiam ser identificadas, comparando os quatro grupos de informantes e o nível de cortesia atribuído por cada grupo aos pedidos que aparecem nos oito vídeos submetidos à sua avaliação.

O pedido presente no vídeo 1 é ambientado na rua, possui baixo grau de imposição, o grau de familiaridade entre os falantes é médio-alto. Além disso, nele há dois modificadores, conforme transcrição a seguir: 
Quadro 6. Transcrição do vídeo 1.

A ah vedi Tinuccia che bei::: che begli appartamenti che ci so:no \# ah: guarda questo quasi quasi mi interessa .h ehm:: volevo prendere il numero di telefono di::. di:: di questo: avviso \# però mi sa che non ho non ho una penna

$\boldsymbol{B}$

$$
[\sqrt{ } \sqrt{ }] \quad \text { [non c'hai da] scrivere? }
$$

A no non ho da scri- eh \#\# hai per caso una penna per piacere?

$\boldsymbol{B}$ [ma perché] [sì guarda io]

A Olha Tinuccia, que... que apartamentos bonitos tem aqui. Ah, olha, esse quase, quase me interessa. Eu queria anotar o número de telefone dessa, dessa placa, mas... acho que não tenho uma caneta.

B Você não tem com o que escrever?

A Não, não tenho... Você tem, por acaso, uma caneta, por favor?

No pedido do vídeo 2, são mantidas as características quanto ao ambiente no qual o pedido acontece e ao grau de imposição. Muda o grau de familiaridade entre os falantes, que desta vez é médio-baixo e não há modificadores. Vejamos.

Quadro 7: Transcrição do vídeo 2.

A eh:: mi scusi ha una penna per scrivere?

B [sì

Eh... me desculpe, tem uma caneta para escrever?

Ao avaliar os níveis de cortesia dos pedidos nos vídeos 1 e 2, os grupos concentraram suas respostas em três níveis. Para o primeiro vídeo, a maioria oscilou entre 3 e 5 e para o segundo, entre 2 e 4 , como mostram as tabelas abaixo. 
Tabela 1. Níveis de cortesia atribuídos ao vídeo $1^{7}$

\begin{tabular}{l|l|l|l|l|l|l|l|l}
\hline \multicolumn{9}{l}{ Vídeo 1 } \\
\hline NC* & \multicolumn{2}{l}{ BR1 } & BR2 & \multicolumn{2}{l}{ IT } & \multicolumn{2}{l}{ ITB } \\
\hline $\mathbf{1}$ & $0 / 19$ & 0 & $1 / 22$ & $4,5 \%$ & $0 / 21$ & 0 & $0 / 20$ & 0 \\
\hline $\mathbf{2}$ & $0 / 19$ & 0 & $0 / 22$ & 0 & $1 / 21$ & $4,8 \%$ & $1 / 20$ & $5 \%$ \\
\hline $\mathbf{3}$ & $7 / 19$ & $\mathbf{3 6 , 8 \%}$ & $6 / 22$ & $27,3 \%$ & $4 / 21$ & $19 \%$ & $4 / 20$ & $20 \%$ \\
\hline $\mathbf{4}$ & $7 / 19$ & $\mathbf{3 6 , 8 \%}$ & $5 / 22$ & $22,7 \%$ & $9 / 21$ & $\mathbf{4 2 , 9 \%}$ & $9 / 20$ & $\mathbf{4 5 \%}$ \\
\hline $\mathbf{5}$ & $5 / 19$ & $26,3 \%$ & $10 / 22$ & $\mathbf{4 5 , 5 \%}$ & $7 / 21$ & $33,3 \%$ & $6 / 20$ & $30 \%$ \\
\hline
\end{tabular}

*NC= nível de cortesia.

Tabela 2. Níveis de cortesia atribuídos ao vídeo 2

Vídeo 2

\begin{tabular}{l|l|l|l|l|l|l|l|l}
\hline NC* & \multicolumn{3}{|l}{ BR1 } & \multicolumn{2}{l}{ BR2 } & \multicolumn{2}{l}{ IT } & \multicolumn{2}{l}{ ITB } \\
\hline $\mathbf{1}$ & $3 / 19$ & $15,8 \%$ & $2 / 22$ & $9,1 \%$ & $1 / 21$ & $4,8 \%$ & $1 / 20$ & $5 \%$ \\
\hline $\mathbf{2}$ & $6 / 19$ & $\mathbf{3 1 , 6 \%}$ & $5 / 22$ & $22,7 \%$ & $5 / 21$ & $23,8 \%$ & $5 / 20$ & $25 \%$ \\
\hline $\mathbf{3}$ & $5 / 19$ & $26,3 \%$ & $12 / 22$ & $\mathbf{5 4 , 5 \%}$ & $5 / 21$ & $23,8 \%$ & $7 / 20$ & $\mathbf{3 5 \%}$ \\
\hline $\mathbf{4}$ & $5 / 19$ & $26,3 \%$ & $2 / 22$ & $9,1 \%$ & $9 / 21$ & $\mathbf{4 2 , 8 \%}$ & $4 / 20$ & $20 \%$ \\
\hline $\mathbf{5}$ & $0 / 19$ & 0 & $1 / 22$ & $4,5 \%$ & $1 / 21$ & $4,8 \%$ & $3 / 20$ & $15 \%$ \\
\hline
\end{tabular}

*NC= nível de cortesia.

A observação da tabela nos permite afirmar que, embora haja certas analogias nas escolhas dos 4 grupos, os brasileiros ainda no início de seus estudos da língua atribuíram tendencialmente níveis de cortesia mais baixos.

7 As porcentagens calculadas com base nos dados foram inseridas nas tabelas com apenas a primeira casa decimal. Isso leva, em alguns casos, a somas que não completam 100\%. Sendo que, nesse momento, nosso objetivo é o reconhecimento de tendências, consideramos suficiente essa indicação quantitativa. 
Vamos agora ao pedido do vídeo número 3. O ambiente é agora a rua, o grau de imposição é alto, o grau de familiaridade médio-alto e há um modificador.

Quadro 8. Transcrição do vídeo 3.

A senti ascolta aspetta che $>$ debbo fare una telefonata $<$ un attimo \# aspetta aspetta B [beh]

A .h ahi è scarico

B vuoi il mio? vuoi il mio?

A [tsc] [sì] sì sì: dammelo perché è urgente la telefonata mi dai il tuo un attimo?

B $[s \grave{l}] \#$

[aspetta aspetta \# devo sbloccarlo te lo passo ecco]

A Ouve, escuta, espera que eu tenho que fazer uma ligação um minuto. Espera, espera.

B $\operatorname{Sim} .$.

A Ai, está descarregado.

B Quer o meu? Quer o meu?

A Sim, sim, me dá porque é urgente a ligação. Me dá o seu um minuto?

B Sim. Espera, espera... Tenho que desbloquear... te dou... aqui está.

No que diz respeito à avaliação da cortesia nesse vídeo 3, as escolhas dos informantes se concentraram nos níveis mais baixos (entre 1 e 3), mostrando novamente avaliações análogas entre os grupos. As similaridades são, no entanto, maiores nos grupos BR2 e IT, sendo que entre eles houve algumas indicações também para os níveis 4 e 5. 
Tabela 3. Níveis de cortesia atribuídos ao vídeo 3

\begin{tabular}{l|l|l|l|l|l|l|l|l}
\hline \multicolumn{7}{l}{ Vídeo 3 } \\
\hline NC* & \multicolumn{2}{l}{ BR1 } & \multicolumn{2}{l}{ BR2 } & \multicolumn{2}{l}{ IT } & \multicolumn{2}{l}{ ITB } \\
\hline $\mathbf{1}$ & $5 / 19$ & $26,3 \%$ & $8 / 22$ & $\mathbf{3 6 , 4 \%}$ & $5 / 21$ & $23,8 \%$ & $2 / 20$ & $5 \%$ \\
\hline $\mathbf{2}$ & $6 / 19$ & $\mathbf{3 1 , 5 \%}$ & $7 / 22$ & $31,8 \%$ & $4 / 21$ & $19 \%$ & $7 / 20$ & $\mathbf{3 5 \%}$ \\
\hline $\mathbf{3}$ & $4 / 19$ & $21,1 \%$ & $3 / 22$ & $13,6 \%$ & $9 / 21$ & $\mathbf{4 2 , 8 \%}$ & $5 / 20$ & $25 \%$ \\
\hline $\mathbf{4}$ & $4 / 19$ & $21,1 \%$ & $2 / 22$ & $9,1 \%$ & $2 / 21$ & $9,5 \%$ & $1 / 20$ & $5 \%$ \\
\hline $\mathbf{5}$ & $0 / 19$ & 0 & $2 / 22$ & $9,1 \%$ & $1 / 21$ & $4,8 \%$ & $5 / 20$ & $25 \%$ \\
\hline
\end{tabular}

*NC= nível de cortesia.

O pedido do vídeo 4 - realizado na rua, com alto grau de imposição, grau de familiaridade médio-baixo e três modificadores - suscitou percepções ligeiramente diferentes entre os grupos. 
Quadro 9. Transcrição do vídeo 4.

A scusi un attimo \# ?che per caso avrebbe un cellulare? sa il mio non mi sta funzionando B [mi dica signora] [?un cellula::re?]!sì certo!

A vediamo un poco se riesco a fare una telefonata perché è una cosa urgente: \# ce l'ha i soldi nel telefono?

B

chiamata signora?] \# penso che ci sia un po' di credito

[deve fare una

A

[posso::: fare] eh

B

[cer]to \#

A Com licença, um momento. Por acaso (o senhor) teria um celular? Sabe, o meu não está funcionando B Me diga, senhora. Um celular? Sim, claro.

A Vejamos se eu consigo fazer uma ligação porque é uma coisa urgente. Tem crédito o seu celular?

C A senhora precisa fazer uma ligação? Acho que tem um pouco de crédito.

A Posso ligar?

B Claro.

Os grupos BR1 e BR2, ao avaliar o vídeo número 4, permaneceram quase todos entre os níveis de 3 a 5, com uma maioria que assinala maior nível de cortesia, enquanto ambos os grupos IT e ITB optaram principalmente pelos níveis de 2 a 4 . As escolhas dos grupos se interseccionam nos níveis 3 e 4, mas os brasileiros atribuíram de modo mais claro um nível de cortesia alto, enquanto os italianos privilegiaram o nível médio-baixo. Assim, nesse caso, parece evidenciar-se uma disparidade entre os grupos de brasileiros e italianos, com os italianos julgando de modo mais rigoroso o diálogo apresentado na gravação. 
Tabela 4. Níveis de cortesia atribuídos ao vídeo 4

\begin{tabular}{l|l|l|l|l|l|l|l|l}
\hline \multicolumn{9}{c}{ Vídeo 4 } \\
\hline NC* & \multicolumn{2}{l}{ BR1 } & \multicolumn{2}{l}{ BR2 } & \multicolumn{2}{l}{ IT } & & \multicolumn{2}{l}{ ITB } \\
\hline $\mathbf{1}$ & $1 / 19$ & $5,3 \%$ & $2 / 22$ & $9,1 \%$ & $2 / 21$ & $9,5 \%$ & $2 / 20$ & $10 \%$ \\
\hline $\mathbf{2}$ & $1 / 19$ & $5,3 \%$ & $2 / 22$ & $9,1 \%$ & $4 / 21$ & $19 \%$ & $7 / 20$ & $35 \%$ \\
\hline $\mathbf{3}$ & $5 / 19$ & $26,3 \%$ & $5 / 22$ & $22,7 \%$ & $7 / 21$ & $\mathbf{3 3 , 3 \%}$ & $4 / 20$ & $20 \%$ \\
\hline $\mathbf{4}$ & $5 / 19$ & $26,3 \%$ & $6 / 22$ & $27,3 \%$ & $7 / 21$ & $\mathbf{3 3 , 3 \%}$ & $4 / 20$ & $20 \%$ \\
\hline $\mathbf{5}$ & $7 / 19$ & $\mathbf{3 6 , 8 \%}$ & $7 / 22$ & $\mathbf{3 1 , 8 \%}$ & $1 / 21$ & $4,8 \%$ & $3 / 20$ & $15 \%$ \\
\hline
\end{tabular}

*NC= nível de cortesia

No vídeo 5, o pedido realiza-se em casa e entre falantes com grau de familiaridade médioalto. O grau de imposição é baixo e há apenas um modificador.

Quadro 10. Transcrição do vídeo 5.

A ciao

B [ciao] Mariana vieni

A [ciao] grazie (per)messo?

B come stai

A [ciao] bene \#.hh a parte il caldo infatti sono:

B [vien vien t'accomodi (sic) accomodati]

A grazie \# .h scusami mi dai un bicchiere d'acqua subito subito che .h sono accaldati:ssima

A Oi.

B Oi, Mariana, entra.

A Oi. Obrigada. Licença?

B Como você está?

A Oi. Bem, fora o calor. Na verdade, eu estou...

B Vem, vem, se acomode, se acomode.

A Obrigada. Desculpa, me dá um copo d'água rápido, rápido, porque eu estou morrendo de calor?

As avaliações dos informantes mostraram-se mais equilibradas e se concentraram entre os níveis 3 e 5, indicando semelhanças na percepção da cortesia: 
Tabela 5. Níveis de cortesia atribuídos ao vídeo 5

\begin{tabular}{l|l|l|l|l|l|l|l|l}
\hline \multicolumn{9}{c}{ Vídeo 5 } \\
\hline NC* & \multicolumn{2}{l}{ BR1 } & \multicolumn{2}{l}{ BR2 } & \multicolumn{2}{l}{ IT } & \multicolumn{2}{l}{ ITB } \\
\hline $\mathbf{1}$ & $2 / 19$ & $10,5 \%$ & $2 / 22$ & $9,1 \%$ & $1 / 21$ & $4,8 \%$ & $1 / 20$ & $5 \%$ \\
\hline $\mathbf{2}$ & $2 / 19$ & $10,5 \%$ & $4 / 22$ & $18,2 \%$ & $3 / 21$ & $14,3 \%$ & $4 / 20$ & $20 \%$ \\
\hline $\mathbf{3}$ & $5 / 19$ & $\mathbf{2 6 , 3 \%}$ & $7 / 22$ & $\mathbf{3 1 , 8 \%}$ & $8 / 21$ & $\mathbf{3 8 , 1 \%}$ & $5 / 20$ & $25 \%$ \\
\hline $\mathbf{4}$ & $5 / 19$ & $\mathbf{2 6 , 3 \%}$ & $5 / 22$ & $22,7 \%$ & $6 / 21$ & $28,5 \%$ & $7 / 20$ & $\mathbf{3 5 \%}$ \\
\hline $\mathbf{5}$ & $5 / 19$ & $\mathbf{2 6 , 3 \%}$ & $4 / 22$ & $18,2 \%$ & $3 / 21$ & $14,3 \%$ & $3 / 20$ & $15 \%$ \\
\hline
\end{tabular}

*NC= nível de cortesia

Ainda sobre o vídeo 5, o exame das porcentagens na tabela revela que não é possível notar uma clara preponderância de nenhum dos níveis de cortesia e que as avaliações são divididas. No grupo BR1, um número igual de informantes optou pelos últimos três níveis, enquanto nos outros grupos a maioria permaneceu na faixa média de avaliação.

Vamos agora à transcrição do vídeo 6 . O pedido realiza-se mais uma vez em ambiente doméstico, o grau de imposição é baixo e há dois modificadores. Interagem falantes com grau de familiaridade médio-baixo.

Quadro 11. Transcrição do vídeo 6.

A eh: buongiorno sono::

B [si accomodi prego] si accomodi eh:

A buongiorno, sono la rappresentante di::

B [le ho dato io (quest) sì: le ho dato] io l'impegno per venire sì

$\mathrm{A}$ eh le volevo\# presentare questo: questo contratto però:

B [ $\left.{ }^{\circ} i^{\circ}\right]$

A prima le devo chiedere un bicchiere d'acqua.

B ah: sicuro come no

A [me lo può dare?]

A Bom dia. Eu sou...

B Se acomode, por favor. Se acomode...

A Bom dia, eu sou a representante de...

B Fui eu quem... Sim, fui eu quem lhe pedi para vir, sim...

A Eu gostaria de lhe apresentar o contrato, mas...

B Sim.

A Primeiro eu devo lhe pedir um copo d'água.

B Sim, como não?

A O senhor pode me dar? 
As avaliações do vídeo 6 também não evidenciaram fortes disparidades: em três dos quatro grupos a maioria dos informantes concentrou-se no nível 4 e apenas o grupo BR2 teve, embora com uma margem percentual mínima, mais indicações para o nível de cortesia 3. No grupo IT, ao contrário de todos os outros, não houve nenhuma vez a indicação do nível 5, sendo que esse foi o grupo que mais atribuiu o nível 1 ao pedido analisado. Observamos, mais uma vez, mais analogias que diferenças.

Tabela 6. Níveis de cortesia atribuídos ao vídeo 6

\begin{tabular}{|c|c|c|c|c|c|c|c|c|}
\hline \multicolumn{9}{|c|}{ Vídeo 6} \\
\hline \multirow{2}{*}{$\begin{array}{l}\mathrm{NC}^{*} \\
\mathbf{1}\end{array}$} & \multicolumn{2}{|l|}{ BR1 } & \multicolumn{2}{|l|}{ BR2 } & \multicolumn{2}{|l|}{ IT } & \multicolumn{2}{|l|}{ ITB } \\
\hline & $0 / 19$ & 0 & $2 / 22$ & $9,1 \%$ & $4 / 21$ & $19 \%$ & $1 / 20$ & $5 \%$ \\
\hline 2 & $4 / 19$ & $21,1 \%$ & $4 / 22$ & $18,2 \%$ & $3 / 21$ & $14,3 \%$ & $4 / 20$ & $20 \%$ \\
\hline 3 & $4 / 19$ & $21,1 \%$ & $7 / 22$ & $31,8 \%$ & $3 / 21$ & $14,3 \%$ & $5 / 20$ & $25 \%$ \\
\hline 4 & $7 / 19$ & $36,8 \%$ & $6 / 22$ & $27,3 \%$ & $11 / 21$ & $52,4 \%$ & $7 / 20$ & $35 \%$ \\
\hline 5 & $4 / 19$ & $21,1 \%$ & $3 / 22$ & $13,6 \%$ & $0 / 21$ & 0 & $3 / 20$ & $15 \%$ \\
\hline
\end{tabular}

*NC= nível de cortesia

Assim como ocorreu com o vídeo 3, a observação das avaliações do vídeo 7 permite que se fale de percepções, em geral, análogas entre os grupos, já que todos selecionaram níveis baixos de cortesia. O pedido presente no vídeo tem alto grau de imposição, ocorre em casa entre falantes com grau de familiaridade médio-alto e é realizado sem a utilização de modificadores. 
Quadro 12. Transcrição do vídeo 7.

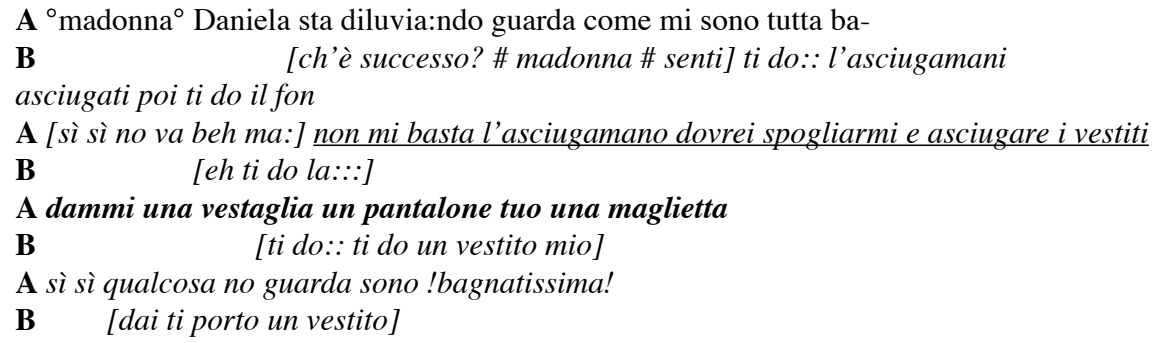

A Nossa, Daniela, está caindo um dilúvio, olha como estou toda molhada!

B O que aconteceu? Nossa... Escuta, vou te dar uma toalha, você se seca e depois eu te dou um secador de cabelo.

A Sim, não, tudo bem... Mas não me basta uma toalha, eu teria que tirar, secar as roupas...

B Eu te dou a...

A Me dá um robe, uma calça, uma camiseta...

B Eu te dou, te dou um vestido meu.

A Sim, alguma coisa... Não, olha, estou ensopada!

B Eu te trago um vestido...

Como se vê na tabela abaixo, os brasileiros concentraram suas escolhas no nível mais baixo de cortesia, enquanto os italianos assinalaram os níveis médio-baixo e baixo. Nesse diálogo parece, então, haver elementos que caracterizam a cortesia, em relação aos quais os dois grupos de brasileiros reagiram de maneira bem mais forte que os italianos. A porcentagem dos informantes brasileiros que atribuíram o menor nível de cortesia (respectivamente, 74\% e 63\%) denota uma nítida predominância da percepção. 
Tabela 7. Níveis de cortesia atribuídos ao vídeo 7

\begin{tabular}{l|l|l|l|l|l|l|l|l}
\hline \multicolumn{7}{c}{ Vídeo 7 } \\
\hline NC* & \multicolumn{2}{l}{ BR1 } & BR2 & IT & \multicolumn{2}{l}{ ITB } \\
\hline $\mathbf{1}$ & $14 / 19$ & $\mathbf{7 3 , 6 \%}$ & $14 / 22$ & $\mathbf{6 3 , 6 \%}$ & $8 / 21$ & $\mathbf{3 8 , 1 \%}$ & $8 / 20$ & $\mathbf{4 0 \%}$ \\
\hline $\mathbf{2}$ & $0 / 19$ & 0 & $5 / 22$ & $22,7 \%$ & $7 / 21$ & $33,3 \%$ & $5 / 20$ & $25 \%$ \\
\hline $\mathbf{3}$ & $3 / 19$ & $15,8 \%$ & $2 / 22$ & $9,1 \%$ & $3 / 21$ & $14,3 \%$ & $3 / 20$ & $15 \%$ \\
\hline $\mathbf{4}$ & $1 / 19$ & $5,3 \%$ & $0 / 22$ & 0 & $2 / 21$ & $9,5 \%$ & $2 / 20$ & $10 \%$ \\
\hline $\mathbf{5}$ & $1 / 19$ & $5,3 \%$ & $1 / 22$ & $4,5 \%$ & $1 / 21$ & $4,8 \%$ & $2 / 20$ & $10 \%$ \\
\hline
\end{tabular}

*NC= nível de cortesia

As características do vídeo 8 são: pedido de alto grau de imposição; ambiente em que se realiza: casa; falantes com grau de familiaridade médio-baixo; presença de três modificadores. 
Quadro 12. Transcrição do vídeo 8.

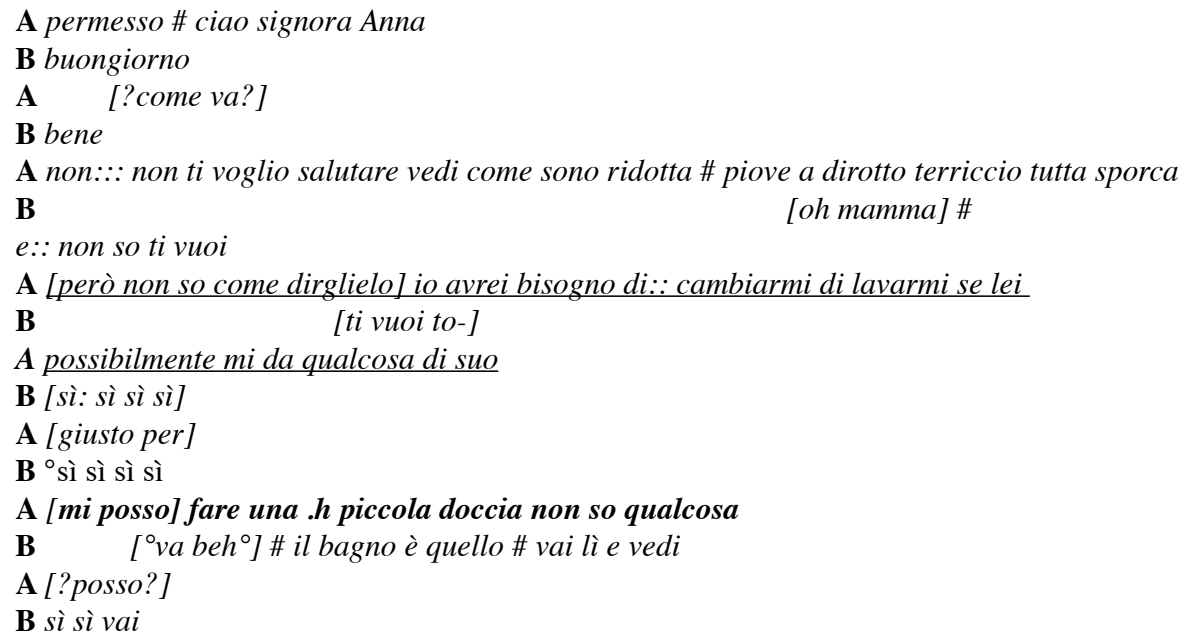

A Com licença. Oi, senhora Anna.

B Bom dia

A Como está?

B Bem.

A Não, não quero te cumprimentar, olha como eu estou, está chovendo muito, estou toda suja.

B Minha nossa... Não sei, você quer se...

A Mas não sei como lhe dizer, eu precisaria me trocar, me lavar, se a senhora...

B Você quer...

A Possivelmente me der algo seu...

B Sim, $\operatorname{sim}, \operatorname{sim}, \operatorname{sim} \ldots$

A Só para...

B Sim, sim, sim, sim...

A Posso tomar um banho rápido, não sei, alguma coisa...

B O banheiro é ali, vai lá e vê...

A Posso?

B Sim, sim, vai... 
Se cada nível de cortesia for analisado separadamente, as avaliações do vídeo 8 foram díspares, embora todos os grupos tenham indicado os níveis médio e alto. Sendo assim, em geral, as avaliações podem ser consideradas análogas. Nos grupos de brasileiros, a maioria atribuiu o nível 5, sendo que nenhum dos italianos residentes na Itália assinalou o nível máximo de cortesia e que também os italianos que residem no Brasil atribuíram tendencialmente níveis de cortesia mais baixos. Vejamos na tabela a seguir:

Tabela 8 . Níveis de cortesia atribuídos ao vídeo 8

\begin{tabular}{|c|c|c|c|c|c|c|c|c|}
\hline \multicolumn{9}{|c|}{ Vídeo 8} \\
\hline \multirow{2}{*}{$\frac{\mathrm{NC}^{*}}{1}$} & \multicolumn{2}{|l|}{ BR1 } & \multicolumn{2}{|l|}{ BR2 } & \multicolumn{2}{|l|}{ IT } & \multicolumn{2}{|l|}{ ITB } \\
\hline & $0 / 19$ & 0 & $2 / 22$ & $9,1 \%$ & $3 / 21$ & $14,3 \%$ & $1 / 20$ & $5 \%$ \\
\hline 2 & $1 / 19$ & $5,3 \%$ & $1 / 22$ & $4,5 \%$ & $2 / 21$ & $9,5 \%$ & $2 / 20$ & $10 \%$ \\
\hline 3 & $7 / 19$ & $36,8 \%$ & $2 / 22$ & $9,1 \%$ & $5 / 21$ & $23,8 \%$ & $7 / 20$ & $35 \%$ \\
\hline 4 & $3 / 19$ & $15,8 \%$ & $8 / 22$ & $36,4 \%$ & $11 / 21$ & $52,4 \%$ & $4 / 20$ & $20 \%$ \\
\hline 5 & $8 / 19$ & $42,1 \%$ & $9 / 22$ & $40,9 \%$ & $0 / 21$ & 0 & $6 / 20$ & $30 \%$ \\
\hline
\end{tabular}

*NC= nível de cortesia

Resumindo, podemos afirmar que, mesmo com algumas diferenças, as respostas dos quatro grupos de informantes mostram mais analogias que diferenças quanto ao nível de cortesia atribuído aos pedidos, tendo como base os dados vistos até agora, já que em 7 dos 8 vídeos foram suscitadas percepções análogas tanto nos dois grupos de italianos quanto nos dois grupos de brasileiros.

Vamos refletir agora sobre as categorias que foram indicadas nas justificativas após a atribuição do nível de cortesia. Como foi dito anteriormente, foram criadas 12 categorias que agrupam as respostas e a décima terceira que serviu para os casos em que não ficou claro o motivo da escolha do nível de cortesia. Algumas foram citadas mais vezes que outras e se alternaram como justificativa mais indicada, dependendo do tipo de pedido e da avaliação de cada informante. Prova disso é que os modificadores - lexicais e morfossintáticos - e o grau de familiaridade foram citados, sem exceção, pelos grupos, mesmo que não tenham servido de justificativa para todos os níveis; em algumas situações, esses elementos foram relevantes 
para um grupo, mas nem chegaram a ser mencionados por outro. No caso do vídeo 5 (baixo grau de imposição/grau de familiaridade médio-alto), por exemplo, o grupo BR2 indicou a categoria do modificador morfossintático 6 vezes para justificar os níveis 1,2, 3 e 4 de cortesia, ao passo que o BR1 não a citou vez alguma. Nas avaliações do vídeo 3, a atitude do interlocutor e, no vídeo 8, o grau de imposição do pedido, mostraram-se mais relevantes para ambos os grupos italianos, mas não para os grupos brasileiros. Por outro lado, certas categorias não foram mencionadas por grupo algum, como o grau de imposição para o vídeo 6 e a atitude do interlocutor para o vídeo 2.

Lembrar que não havia categorias predefinidas às quais os informantes pudessem recorrer para justificar a atribuição do nível de cortesia presente em cada pedido é de grande relevância para responder se é possível reconhecer uma correlação entre as diferentes categorias e o nível de cortesia: cada informante, para cada nível, apontou o elemento que lhe parecia mais adequado, o que permitiu que cada categoria pudesse ser associada a diversos níveis.

A categoria dos modificadores lexicais, nas avaliações do vídeo 3, foi apontada para justificar a seleção tanto do nível baixo quanto do médio e do médio-alto. A forma de tratamento, por sua vez, foi citada significativamente nas avaliações dos pedidos dos vídeos 2, 5, 6, 7 e 8 (que têm características muito variadas entre si quanto ao grau de imposição e de familiaridade), justificando - em maior ou menor proporção - todos os níveis de cortesia. Nossa hipótese é que, como existem vários elementos que colaboram para uma determinada percepção, a absoluta liberdade dos informantes impediu que eles privilegiassem alguns.

Para determinar se há a possibilidade de o contato prolongado com a outra língua e cultura modificar a percepção da cortesia, é preciso fazer algumas observações. Ao avaliar o vídeo 2, por exemplo, o grupo ITB mencionou a presença de modificadores lexicais tanto quanto o grupo BR2. A partir disso, duas hipóteses parecem ser plausíveis: por um lado, o grupo ITB pode ter tido esse comportamento por conta do contato com os brasileiros; por outro, o grupo BR2, pelo maior contato com a língua e a cultura italianas, pode ter modificado sua percepção. De qualquer maneira, seria possível dizer que o contato entre as duas línguas e culturas tende a tornar os resultados mais próximos. Ao justificar os níveis de cortesia atribuídos ao vídeo 3, BR1 e IT citaram a mesma quantidade de vezes o fato de que o pedido ali presente parecia uma ordem. Essa percepção poderia ser resultado do contato (ainda que breve) desse grupo de brasileiros com a língua italiana ou uma coincidência no modo de brasileiros e italianos perceberem os mesmos fatos linguísticos. Pensando no vídeo 7, tanto o grupo BR1 quanto o 
grupo IT mencionaram significativamente o grau de familiaridade entre A e B, entretanto, o grupo ITB foi aquele que atribuiu a maior relevância a esse aspecto entre todos os grupos. Tal comportamento pode fazer crer que uma característica comum a brasileiros e italianos possa ter sido potencializada no grupo ITB pela convivência com brasileiros.

\section{Considerações finais}

Os dados que resultaram da pesquisa realizada mostram, aparentemente, analogias entre as percepções de italianos e brasileiros em todos os grupos apresentados. Os vídeos utilizados como ponto de partida para eliciar os dados coletados foram todos julgados pelos informantes e serviram para a atribuição de níveis de cortesia que se revelaram, no entanto, muito difusos, de modo que em apenas um caso ficaram evidentes tendências mais claras em uma direção e com diferenças entre italianos e brasileiros.

Embora o número de informantes possa ser considerado adequado para uma pesquisa exploratória como esta, tendo permitido uma primeira análise e fornecido dados com os quais pudemos responder às perguntas de pesquisa, o estudo precisará ser aprofundado, tanto observando de maneiras diferentes esses mesmos dados, que podem oferecer outras informações, quanto continuando e ampliando a duração da pesquisa e o número de informantes de modo a aumentar a confiabilidade dos dados e melhorar sua qualidade.

Com aproximadamente 20 indivíduos em cada grupo, foi possível identificar tendências, mas não estabelecer padrões sobre a percepção da cortesia por parte de brasileiros e italianos. Uma pesquisa futura poderá também partir das categorias indicadas e reconhecidas nesta fase para já oferecer aos participantes algumas opções. Isso poderá permitir que as respostas se concentrem e forneçam maiores detalhes.

Além disso, os dados obtidos e as descrições dos informantes podem ensejar uma reflexão mais sistemática sobre as contribuições que esse tipo de pesquisa pode fornecer ao ensino a alunos brasileiros de italiano de aspectos ligados à cortesia linguística, tornando-se assim um meio para a formação de professores que podem, com instrumentos dessa natureza, ganhar mais consciência sobre fenômenos ligados à língua e à cultura dos quais, em grande medida, depende o sucesso da comunicação. 


\section{Referências}

AUSTIN, J. L. How to do things with words. Oxford: Clarendon Press, 1962.

BAZZANELLA, C. Linguistica e pragmatica del linguaggio: un'introduzione. Roma-Bari: Laterza, 2008.

BLUM-KULKA, S.; HOUSE, J.; KASPER, G. Investigating Cross-Cultural Pragmatics: An Introductory Overview. In . (orgs.). Cross-Cultural pragmatics: Requests and Apologies. Norwood, NJ: Ablex, 1989, p. 1-28.

BROWN, P.; LEVINSON, S. Politeness: some universals in language use. Cambridge: Cambridge University Press, 1987.

CARREL, P. L.; KONNEKER, B. H. Politeness: comparing native and nonnative judgments. In Language Learning - A Journal of Applied Linguistics, Michigan: v. 31 (1): 17-29, jun. 1981.

FAERCH, C.; KASPER, G. Internal and External Modification in Interlanguage Request Realization. In BLUM-KULKA, S.; HOUSE, J.; KASPER, G. (orgs.). Cross-Cultural pragmatics: Requests and Apologies. Norwood, NJ: Ablex, 1989, p. 221-246.

GRICE, H. P. Logic and Conversation. In COLE, P.; MORGAN, J (orgs.). Syntax and Semantics 3: speech acts. New York: Academic Press, (1975 [1967]), p. 41-58.

LAKOFF, R. The logic of politeness; or minding your P's and Q's. In CORURM, C. et al. (eds.). Papers from the Ninth Regional Meeting of the Chicago Linguistic Society, 1973.

MARIOTTINI, Laura. La Cortesia. Roma: Carocci, 2007.

NUZZO, E. Imparare a fare cose con le parole. Richieste, proposte, scuse in italiano lingua seconda. Perugia: Guerra, 2007.

; GAUCI, P. Insegnare la pragmática in italiano L2: Recenti ricerche nella prospettiva della teoria degli atti linguistici. Roma: Carocci, 2012.

PIZZICONI, B. Re-examining politeness, face and the Japanese language. In Journal of Pragmatics, 35: 1471-1506, 2003.

SANTORO, E. A constituição de um corpus de italiano falado para o estudo de pedidos e pedidos de desculpas: considerações sobre a validade interna e externa dos dados. In MELLO, H.; PETTORINO, M.; RASO, T. (orgs.). Proceedings of the VII GSCP International Conference: Speech and Corpora. Firenze: Firenze University Press, 2012.

SEARLE, J. R. Speech Acts. An Essay in the Philosophy of Language. New York: Oxford University Press, 1969. 
THOMAS, J. Cross-Cultural Pragmatic Failure. In Applied Linguistics, 4: 91-112, 1983.

TRASK, R. L. Dicionário de linguagem e linguística. Trad. Rodolfo Ilari. 3.ed. São Paulo: Contexto, 2004.

VILLAÇA, I. G.; BENTES, A. C. Aspectos da cortesia na interação face a face. In PRETI, D. (ed.). Cortesia Verbal. São Paulo: Humanitas, 2008. 